\section{MULTIVALUE: A BASIC program for computing theoretical predictions for simple and multivalued coalition games}

\author{
TIMOTHY B. HEATH \\ University of Iowa, Iowa City, lowa
}

and

\author{
CHARLES E. MILLER \\ Northern Illinois University, DeKalb, Illinois
}

MULTIVALUE is a computer program for calculating the predictions of two theories of coalition formation: bargaining theory (Komorita \& Chertkoff, 1973; Komorita \& Tumonis, 1980) and the equal excess model (Komorita, 1979). Recent reviews of coalition research, including discussions of these two theories, may be found in Komorita (1984) and Komorita and Kravitz (1983).

Laboratory research on coalition formation typically employs games in which a group of players has an opportunity to form any one of several possible coalitions, each composed of a different subset of the players. By forming coalitions, players can earn some sort of payoff (e.g. , points or money). For a coalition to form, however, all members of the coalition must agree on how to divide the payoff.

Early coalition research focused on simple games, in which all coalitions either "win" or "lose." All winning coalitions are worth the same amount (e.g., 100 points), and all losing coalitions are worth a smaller amount (e.g., 0 points). Recent research, however, has been primarily concerned with variable-payoff or multivalued games (Komorita \& Kravitz, 1983), in which there are differences in payoffs for the possible winning coalitions. One reason for the increased popularity of multivalued games is that they are more representative of "real world" situations than are simple games.

An important finding of coalition research is that players' behavior changes as a function of their familiarity and experience with coalition games. Although there are many theories of coalition formation, only bargaining theory and the equal excess model are expressly designed to predict such changes in coalition behavior. Although these two theories often make similar predictions with respect to coalition formation and the payoff split (Komorita, 1984), it is possible to construct games for which clearly opposing predictions are made (see Urruti \& Miller, 1984). Likewise, it is possible to test the predicted effects of experience and familiarity by con-

Requests for reprints should be sent to Charles E. Miller, Department of Psychology, Northern Ilinois University, DeKalb, IL 60115. structing games in which the predicted effects range from relatively small to relatively large. A problem with such comparative approaches is that calculating the theoretical predictions is a cumbersome and time-consuming procedure in which it is easy to make mistakes. This problem is partly solved by Kravitz and Walker's (1984) computer program COALPRED. Unfortunately, COALPRED is limited to simple games; it is incapable of making predictions for multivalued games. MULTIVALUE was developed to generate predictions for both simple and multivalued games. This program should encourage researchers to examine predictions for a variety of games, in an effort to find games that will provide the strongest test of the theoretical issues under consideration.

Program Input. MULTIVALUE allows the user to specify the coalition game by entering either the characteristic function (coalition values) or, in the case of apex games, the quota values of the players (Horowitz, 1973). If the game is specified by its characteristic function, the user must indicate the number of possible winning coalitions (all other coalitions are assigned zero payoff). If the game is specified in terms of quotas, the user must indicate the number of players. Users also specify whether they want the predictions of one or both theories, and the number of rounds, in multiples of seven, for which they would like predictions of the equal excess model.

Program Output. MULTIVALUE lists the values of all possible winning coalitions in the game and the payoff divisions predicted by the specified theories. For bargaining theory, both initial and asymptotic predictions are given. For the equal excess model, predictions are given for all the rounds, until the maximum number of rounds specified by the user is reached. Predicted payoffs are printed to one decimal place, although the actual calculations are more precise.

MULTIVALUE will make predictions for games to which the theories do not actually apply. For example, neither bargaining theory nor the equal excess model is, strictly speaking, applicable to games in which one or more players have only one coalition available to them. MULTIVALUE will make the calculations for such games by treating players with only one potential coalition as though they had alternative coalitions with zero value.

Limitations. MULTIVALUE is limited to games involving six or fewer players and 15 or fewer positively valued coalitions. In addition, MULTIVALUE will not make predictions for games in which the players are assigned resources (i.e., resources are not a variable in the program and will be ignored).

Documentation. MULTIVALUE is accompanied by documentation describing the mechanics of the program and the conceptual frameworks of the bargaining theory and equal excess model.

Language and Computer. MULTIVALUE is written in BASIC and was developed on a Prime-850 minicom- 
puter. It has also been adapted for the Kaypro K-11, Altos Series 5-15DA, and DEC PDP/11-45 computers. Because the program does not create or access any external data sets, adapting the program to other systems requires only minor syntactic adjustments to the code.

Availability. Paper or 5.25-in floppy disk copies of the program as adapted for the Kaypro K-11 and Altos Series 5-15DA are available at cost (approximately $\$ 5$ for the disk and $\$ 1$ for the paper) from Charles E. Miller. A paper copy of the program adapted for the Prime-850 is also available at cost. Finally, floppy disk copies of the Kaypro version of the program can be reformatted for the following machines and systems, regardless of whether the disks are single- or double-sided: Actrix, Cromemco, Dataview, DEC, Epson, Heath, HP, IBM, IMS, Lobo, Magic, Morrow, NEC, Osborne, Otrona-Attache, Sanyo, Superbrain, Televideo, Toshiba, TRS-80, Xerox, and Zenith. It should be noted that although the disk can be reformatted for a particular system, the user will need to make minor syntactic adjustments in order for the program to be compatible with the BASIC of the user's system.

\section{REFERENCES}

Horowitz, A. D. (1973). The competitive bargaining set for cooperative n-person games. Journal of Mathematical Psychology, 10, 265-289.

Komorita, S. S. (1979). An equal excess model of coalition formation. Behavioral Science, 24, 369-381.

Komorita, S. S. (1984). Coalition bargaining. In L. Berkowitz (Ed.), Advances in experimental social psychology. New York: Academic Press.

Komorita, S. S., \& Chertkoff, J. M. (1973), A bargaining theory of coalition formation. Psychological Review, 80, 149-162.

Komorita, S. S., \& Kravitz, D. A. (1983). Coalition formation: A social psychological approach. In P. Paulus (Ed.), Basic group processes (pp. 179-203). New York: Springer-Verlag.

Komorita, S. S., \& Tumonis, T. (1980). Extensions and tests of some descriptive theories of coalition formation. Journal of Personality \& Social Psychology, 39, 256-268.

Kravitz, D. A., \& Walker, J. A. (1984). COALPRED: A BASIC program for computing the predictions of five coalition theories. $B e$ havior Research Methods, Instruments, \& Computers, 16, 69-70.

URRUTI, G., \& MILLER, C. E. (1984). Test of the bargaining and equal excess theories of coalition formation: Effects of experience, information about payoffs, and monetary stakes. Journal of Personality \& Social Psychology, 46, 825-836.

(Revision accepted for publication June 21, 1985.) 